\title{
WAVE LOADING FOR RECURVED PARAPET WALLS IN NON-BREAKING WAVE CONDITIONS: ANALYSIS OF THE INDUCED IMPULSIVE FORCES.
}

\author{
Myrta Castellino ${ }^{1}$, Javier L. Lara² ${ }^{2}$ Alessandro Romano ${ }^{1}$, Iñigo J. Losada ${ }^{2}$, Paolo De Girolamo ${ }^{1}$ \\ This paper describes 2-D numerical simulations aiming to reproduce the pressure impulse named confined-crest \\ impact (Castellino et al., 2018), which occurs when a recurved parapet wall and non-breaking wave conditions are \\ interacting. The simulations are carried out by using the IH2VOF and IHFOAM, the latter developed as OpenFOAM \\ additional library. The results show a large increase of the pressures and forces value when the recurved part of the \\ vertical parapet results completely occluded by the non-breaking wave crest. A sensitivity analysis has been carried \\ out to study the influence of the geometrical parameters (radius $\mathrm{r}$ and opening angle $\alpha$ ). It has been found a low \\ variability with respect to the radius increase (from $1.0 \mathrm{~m}$ to $2.0 \mathrm{~m}$ ) and a higher influence related to the opening \\ angle variation. Finally, the non-dimensional force component has been represented as a function of the hydraulic \\ and geometrical parameters by means of the dimensionless product $(1 / \mathrm{h}) *$ s. These parameters represent the overhang \\ extension seaward of the parapet, the water depth and the wave steepness with reference to deep-water conditions.
}

Keywords: vertical breakwater; recurved parapet; non-breaking waves; CFD simulations

\section{INTRODUCTION AND STATE OF THE ART}

Vertical breakwaters are a type of coastal structure used in non-breaking wave conditions to protect harbours from incoming waves (typically non-breaking). Sometimes in order to safely use the port-side of these breakwaters, it is crucial to limit wave overtopping. In order to do this, a technical solution, among others, is to build recurved superstructures. This solution allows maintaining the crest elevation as low as possible, and reducing wave overtopping at the same time.

The wave structure interaction has been deeply studied for the cases of seawalls and storm walls, where the main hydrodynamic conditions are represented by breaking wave conditions. Typical examples of a curved-faced seawall are reported in Figure 1.

This kind of passive structure is often used at locations of exposed city fronts, where good protection is needed to protect the coast against erosion and flooding. Seawalls are widespread in the north of Europe along the Dutch, Danish and German coasts, including also Great Britain. An extensive review of curved seawall shapes can be found in Anand et al. (2010).

Recent applied research concerning breaking wave loads and their effects at vertical seawalls and at caisson breakwaters may be found in Cuomo et al. (2010a, b, 2011) and Elsafti and Oumeraci (2017).

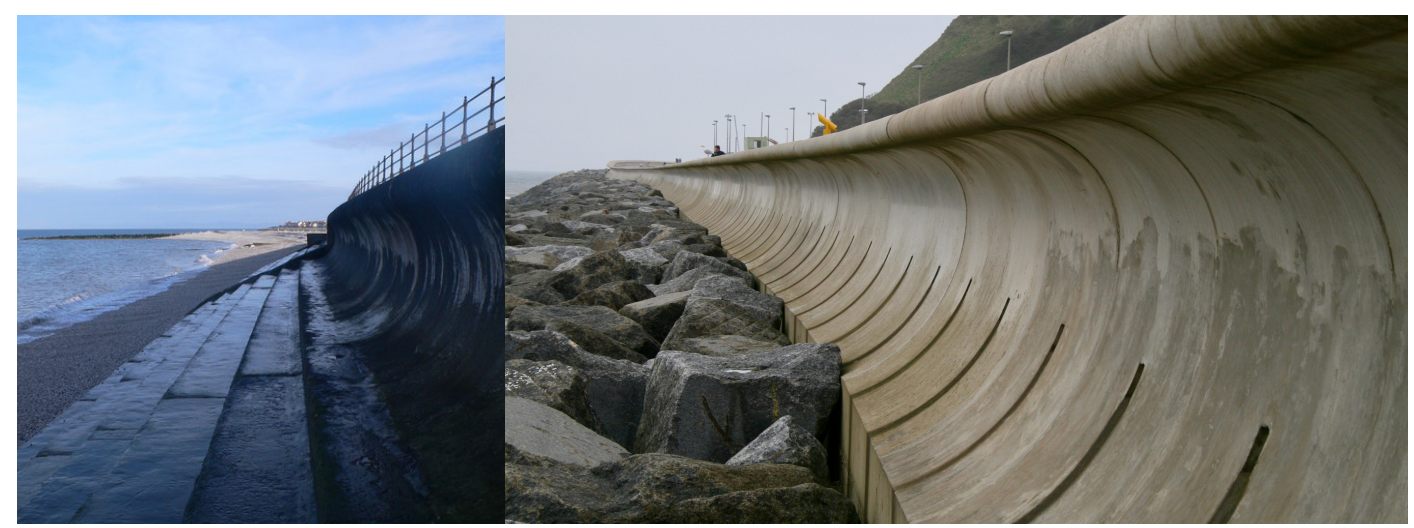

Figure 1. Wave return wall located in Penrhyn Bay, Great Britain reported in the left panel. Recurved seawall with rock armour at Scarborough reported in the right panel.

\footnotetext{
1 "Sapienza" University of Rome,DICEA Department, Via Eudossiana 18, Rome, Italy, 00184

2 Environmental Hydraulics Institute "IH Cantabria", Universidad de Cantabria, C/Isabel Torres no. 15, Parque Cientifico y Tecnologico de Cantabria, 39011 Santander, Spain
} 
Van Doorslaer et al. (2017) considered the impact on storm walls induced by overtopping flow using a different approach to calculate the impact forces on the wall. On the same subject, Kortenhaus et al. (2015) have studied both wave overtopping and wave induced loads on coastal storm walls caused by overtopping waves, always considering shallow water conditions.

One of the first studies on the application of curved crownwalls on composite vertical breakwaters was conducted by De Gerloni et al. (1989) for the deep water perforated caissons at Porto Torres, testing different recurve shapes with excellent wave overtopping reduction. Even field measurements of pressures acting on the Porto Torres caissons were then carried out by De Girolamo et al. (1996), but no large events were recorded in the limited measurement period. General formulations for wave overtopping reduction factors, as compared to the pure vertical wall, were then proposed by Franco et al. (1995), while recent effective applications were described by Di Risio et al. (2007, 2009) and Franco et al. (2013).

To date, the formulae for estimating the magnitude of impulsive and non-impulsive pressure fields, acting on composite vertical breakwaters and generated by breaking and non-breaking waves, are largely derived from the results of laboratory tests. The most widely used design formulae are summarized by Goda (2010). These formulae include impulsive breaking conditions studied by Takahashi (1996) in which new parameters have been introduced to describe the typical church-roof shape related to the pressure time series.

The first works that highlighted the effects of recurved walls on the total force acting on a coastal structure, due to breaking and non-breaking waves, are those of Kortenhaus et al. (2002) and Kortenhaus et al. (2004), which refer to the results relates to the European project EC CLASH. They investigated experimentally the effects of parapets and recurves on wave overtopping and wave loading. The authors found that the horizontal force increase is about 1.7 for impulsive breaking wave conditions and 2.0 for non-breaking conditions. But as reported by the authors: "These numbers do not however distinguish whether the increase of loading result from the increase of wall height or the shape of the wall installed at the wall".

Castellino et al. (2018), proposed a new approach to study the impact induced by non-breaking waves hitting a recurved surface. They used the numerical model IHFOAM, reproducing only regular waves, to enucleate the physics of these impacts by considering a simple geometry and by comparing the hydrodynamic features, induced by the recurved parapet, eith the ones occurring on a traditional plane parapet wall. As a result, it was found that the increase of the force in the case of a recurved parapet is of about 2.8 times the force obtained for the same wave on a traditional plane parapet wall. The same numerical findings pointed out by Castellino et al. (2018) have been confirmed by the experimental study carried out by Martinelli et al. (2018).

In this paper, a comparison between the results obtained by Castellino et al. (2018) and those of a 2D single-phase flow model (IH2VOF) is proposed together with an improved sensitivity analysis to study the influence of the structural geometrical parameters on the force increase. The present paper is structured as follows. After this introduction the description of the numerical simulations is provided, then a section of results and conclusions closes the paper.

\section{DESCRIPTION OF THE NUMERICAL SIMULATIONS}

Numerical simulations have been performed initially by using IH2VOF (Lara et al., 2008, 2011) and IHFOAM (Higuera et al., 2013a, b, 2014a, b), reproducing the numerical simulations described in Castellino et al. (2018). The main differences between these two models is related to the flow phases and to the object inclusion in the numerical domain.

Both the models take into account the VOF method (Berberovich et al., 2009) to track the free surface, but if in IHFOAM two phases are considered (air and water), in IH2VOF only the water phase is present. This permits theoretically to save the computational time cost, solving the Reynolds average Navier-Stokes equation only for the water phase. 


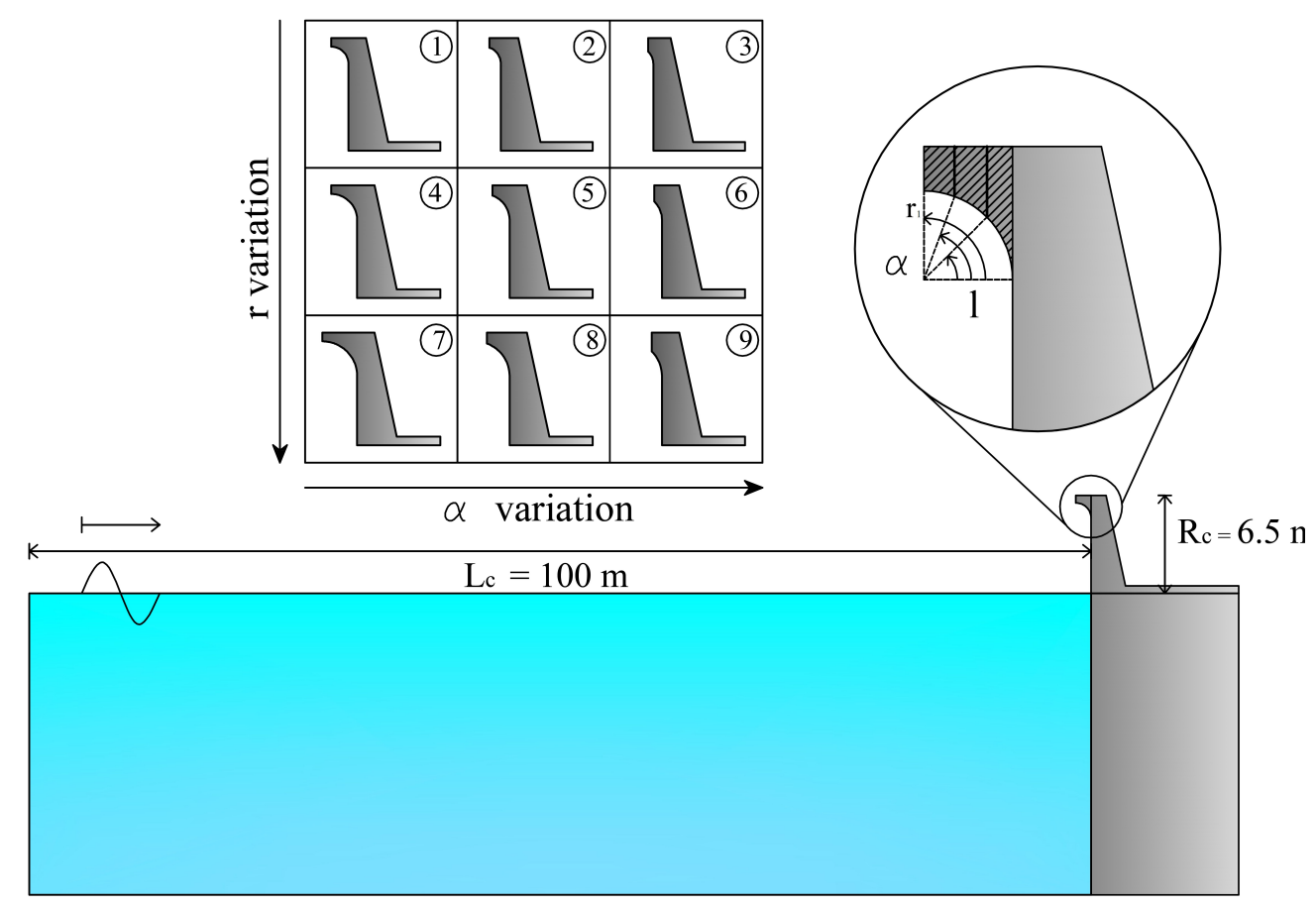

Figure 2. Setup of the implemented geometries. The parameters variation refers to the opening angle $\alpha$ and the radius $r$.

For what concerns the numerical setup adopted for the IH2VOF simulations, a wave flume $100 \mathrm{~m}$ long and $40 \mathrm{~m}$ high has been considered (see lower panel of Figure 2), exactly reproducing the dimensions considered in Castellino et al. (2018). The mesh is characterized by fixed discretization along the $\mathrm{x}$ and $\mathrm{z}$-axis (the $\mathrm{z}$-axis is the vertical one), where $\Delta \mathrm{x}=\Delta \mathrm{z}=0.05 \mathrm{~m}$. Considering such a thick discretization is due to the need to model a recurved surface by means of a structured mesh. An example of the adopted discretization is illustrated in Figure 3, the left panel represents the IH2VOF mesh while in the right panel those of the IHFOAM. Both the mesh schemes are magnified in the lower panels. Looking at the lower left panel (IH2VOF) it can be noticed that even with a refined mesh the object surface results made of different steps and not by a smooth surface. In OpenFOAM with the body-fitted mesh approach it is possible to perfectly adapt the cells around the recurved part of the wall, allowing to consider a larger mesh far from the structure.

In Figure 2 the geometrical setups of the structure are shown, as well as the dimensions of the wave flume (lower panel), highlighting the main parameters of the recurved parapet (the opening angle $\alpha$ and the radius $r$ ). The variation of both the parameters has been taking into account as shown in Figure 2 (upper panel). The opening angle ranged between $0^{\circ}$ (plane parapet wall) and $90^{\circ}$ (with the intermediate angles equal to $45^{\circ}$ and $70^{\circ}$ ). The radius values considered are $1.0 \mathrm{~m} 1.5 \mathrm{~m}$ and $2.0 \mathrm{~m}$. The higher panel of the figure shows this variation. Moving from top to bottom the radius varies while, moving from left to right the opening angle varies. All the structures are characterized by freeboard $\mathrm{R}_{\mathrm{c}}$ equal to $6.5 \mathrm{~m}$. The water depth has been considered as a fixed parameter as well as the freeboard, equal to $\mathrm{h}=20.0 \mathrm{~m}$.

For what concern the boundary conditions, these are exactly the same for IH2VOF and IHFOAM models. Along the inlet (west side of the numerical flume) the wave generation and active absorption have been placed. The structures have been considered as impermeable objects.

Only regular wave conditions have been performed varying both the wave height and period. The regular wave characteristics are listed in Table 1. For each numerical test, some 15 waves have been simulated. 


\begin{tabular}{|c|c|c|}
\hline \multicolumn{3}{|c|}{$\begin{array}{c}\text { Table 1. Characteristics of the } \\
\text { wave conditions performed. }\end{array}$} \\
\hline & $\mathrm{H}(\mathrm{m})$ & $\mathrm{T}(\mathrm{s})$ \\
\hline W4 & 4.0 & 8.0 \\
W5 & 5.0 & 8.0 \\
W6 & 6.0 & 8.0 \\
W7 & 7.0 & 11.0 \\
\hline
\end{tabular}

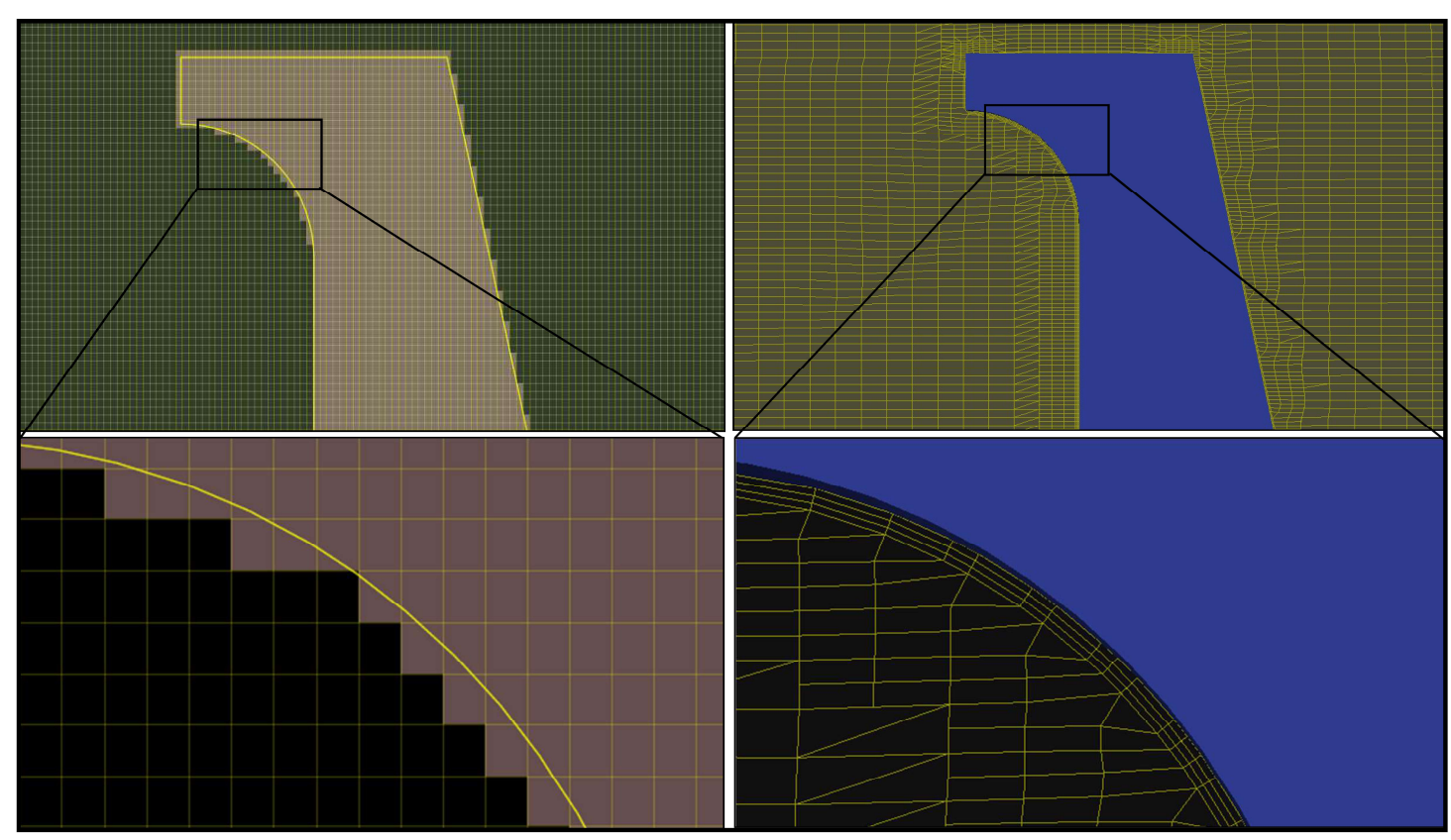

Figure 3. Mesh example adopted in IH2VOF (left panel) and IHFOAM (right panel). From the left panel it is possible to see the level of refinement of the mesh adopted within the IH2VOF simulations. In the right panel, an example of the body-fitted mesh is reported.

\section{RESULTS AND CONCLUSIONS}

Numerical simulations, as reported in Castellino et al. (2018) have shown that the presence of the recurved parapet induces a very large increase of wave pressure acting on quite a large part of the entire structure, compared to the case where the parapet is completely vertical. The impulsive impact has been called "confined-crest impact". This definition could be explained looking at the free surface evolution reported in Figure 4, linked to the velocity (right panels of the figure) and pressure (left panels of the figure) fields. In the figure, three times are considered. Starting from the top panels, the wave crest reaches half of the recurve, no pressure nor velocity increase are observed.

At the second time (middle panels), referring to the pressure field represented in the left panel, when the wave crest has almost reached the tip of the parapet, a local pressure increase occurs just under the free surface toward the structure. The total velocity (right panel) near the wall tends to focus seaward, allowing the wave to "exit" from the parapet following the curve.

At the third time (lower panels), when the wave front reaches the very tip of the recurve, a high pressure increase occurs in a sector ranging between $45^{\circ}$ and $90^{\circ}$. The exit jet velocity is found in the example reported being of the order of $30 \mathrm{~m} / \mathrm{s}$.

Hence, the large pressure impulse realizes when the recurved part of the wall is completely confined by the wave crest. 

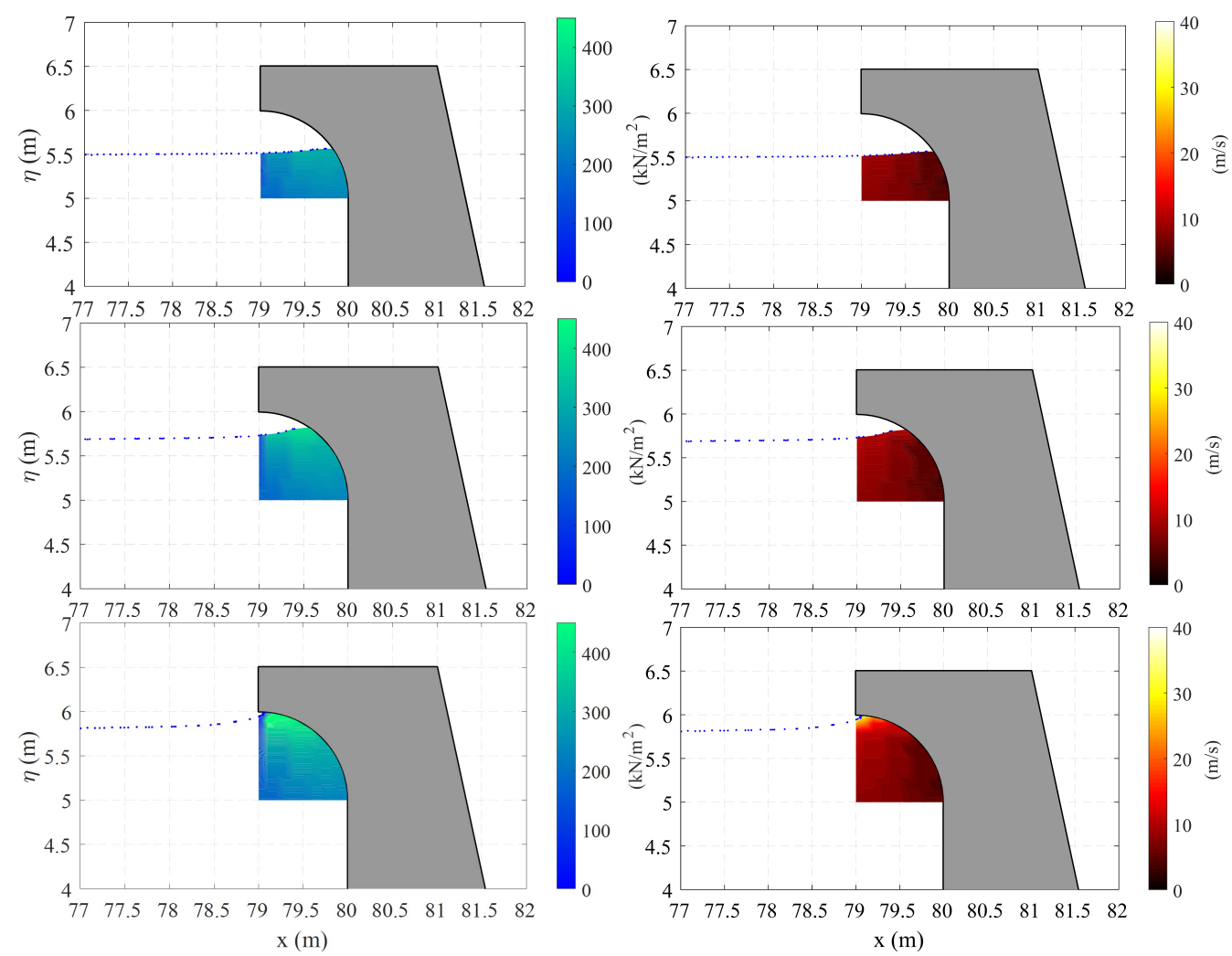

Figure 4. Free surface, pressure and velocity field evolution all around the recurve. The left column represent the pressure field while the right column the total velocity field. The third instant of complete confinement of the recurved part is the instant at which the crest-confinement impact occurs.

The comparison between the two models results is proposed in terms of pressures and total forces in Figures 5 and 6 respectively. Figure 5 shows the dynamic pressure distributions along the structure (caisson and parapet) evaluated at the instant at which the maximum force occurs along the emerged part of the structure. The pressure time series have been measured by means of a series of numerical pressure probes. The results are proposed for all the simulations where the red line refers to the IH2VOF while the black one to the IHFOAM results. It is possible to observe a very good accordance between the distributions of the pressure.

In Figure 6, the overall results are shown in terms of total force $F_{\text {rmax }}$. The force is calculated by considering the numerical integration of the pressure time series recorded by the numerical probes placed along the parapet. It is important to stress the importance of the acquisition frequency which must be considerably high to detect the impulsive pressure. It is well known that this kind of pressure realizes in a very short time interval. The IH2VOF results refer to an acquisition frequency of $1000 \mathrm{~Hz}$, while for the IHFOAM simulation a data every time-step has been registered (varying on average between $500 \mathrm{~Hz}$ and $2000 \mathrm{~Hz}$ ), allowing to capture impulsive phenomena. The scatter plot of Figure 6 shows a slight underestimation of IH2VOF results increasing the wave height and period.

Even if the results are in a really good accordance, no more analysis have been done by using the IH2VOF model. This choice is linked to the "rigidity" of the mesh, which must be very coarse to perfectly model the recurved structure. This leads to an increase of the computational time costs, unlike what a single-phase flow should require.

As stated before, nine geometrical setups have been considered to study the influence of the radius and of the opening angle on the impulsive component of the force acting on the structure (see Figure 2). The first results are reported in Figure 7, where the non-dimensional total forces $\mathrm{F}^{*}{ }_{\text {rmax }}$ are calculated with respect to the emerged part of the vertical breakwater and represented as a function of the non- 

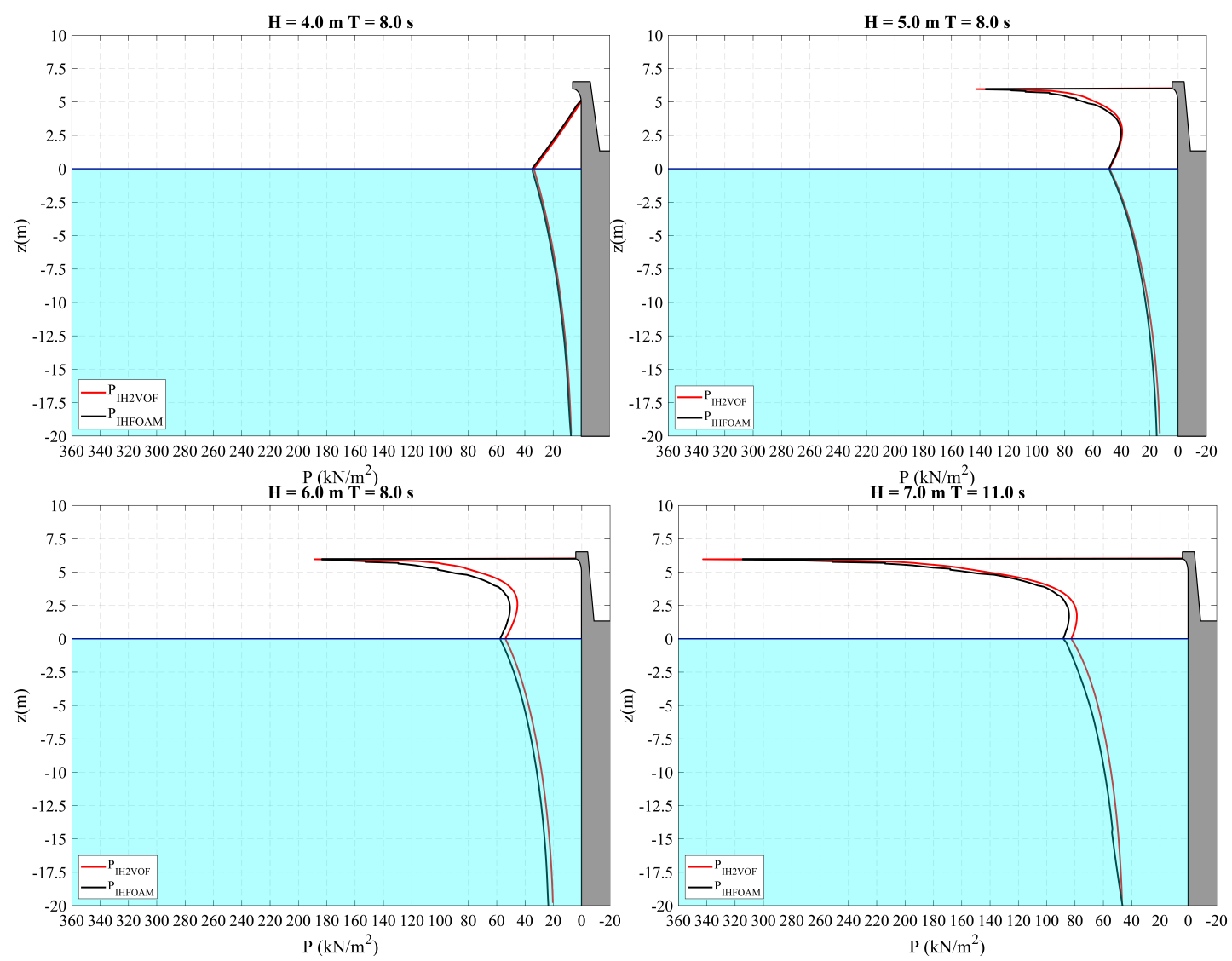

Figure 5. Comparison between the pressures obtained at the maximum force instant. The red line refers to the IH2VOF while the black line to the IHFOAM results.

dimensional freeboard $\mathrm{R}_{\mathrm{c}} / \mathrm{H}$. These forces are made non-dimensional by dividing each value for the corresponding force acting on the plane parapet $\left(\alpha=0^{\circ}\right)$.

In the left panel of Figure 7, the coloured groups, blue red and green respectively, refers to the three opening angle of $90^{\circ}, 70^{\circ}$ and $45^{\circ}$ respectively. The obtained results confirm what was found by Castellino et al. (2018). The non-dimensional force appears to grow linearly, increasing the wave height $\mathrm{H}$, until reaching a threshold value. The non-dimensional force seems to remain constant varying both the wave height and period after the threshold point. The maximum force increase is of the configuration with the $90^{\circ}$ opening angle and equal to 3. This means that the force on the recurved parapet is three times the force on a standard vertical parapet wall. As a conclusion, from the comparison between the non-dimensional force and freeboard, it is found that the radius parameter does not much influence the force increase.

In the right panel of the Figure 7 the last analysis is shown. The relation between the nondimensional force component and the $l / h *_{s}$ parameter has been considered, with $l$ representing the overhang seaward extension, $h$ the water depth and $s$ the wave steepness in deep water condition. The combination of these hydraulic and geometrical factors seem to well describe the vertical force component, where the fitting curve (a straight line) is characterized by a coefficient of determination $\mathrm{R}^{2}$ $=0.76$.

In conclusion, a comparison between the results obtained by using the IH2VOF and IHFOAM are presented in terms of total forces Frmax, calculated on the superstructure of the vertical breakwater, and pressure distribution along the entire structure. The results are in very good agreement. Nevertheless, the computational time costs required by IH2VOF are much higher than those of IHFOAM. This is due to the need of modelling a recurved surface with a structured mesh (IH2VOF) instead of the body-fitted mesh that allow using a larger cell size also not far from the structure. 


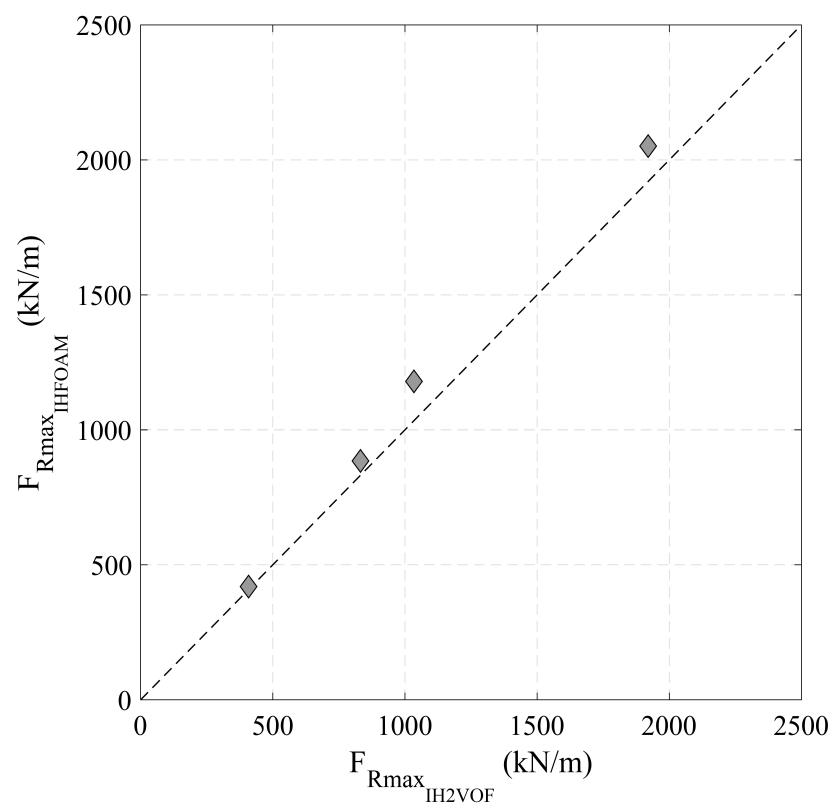

Figure 6. Comparison between the maximum force values obtained by means of IH2VOF and IHFOAM. The results show a very good agreement.
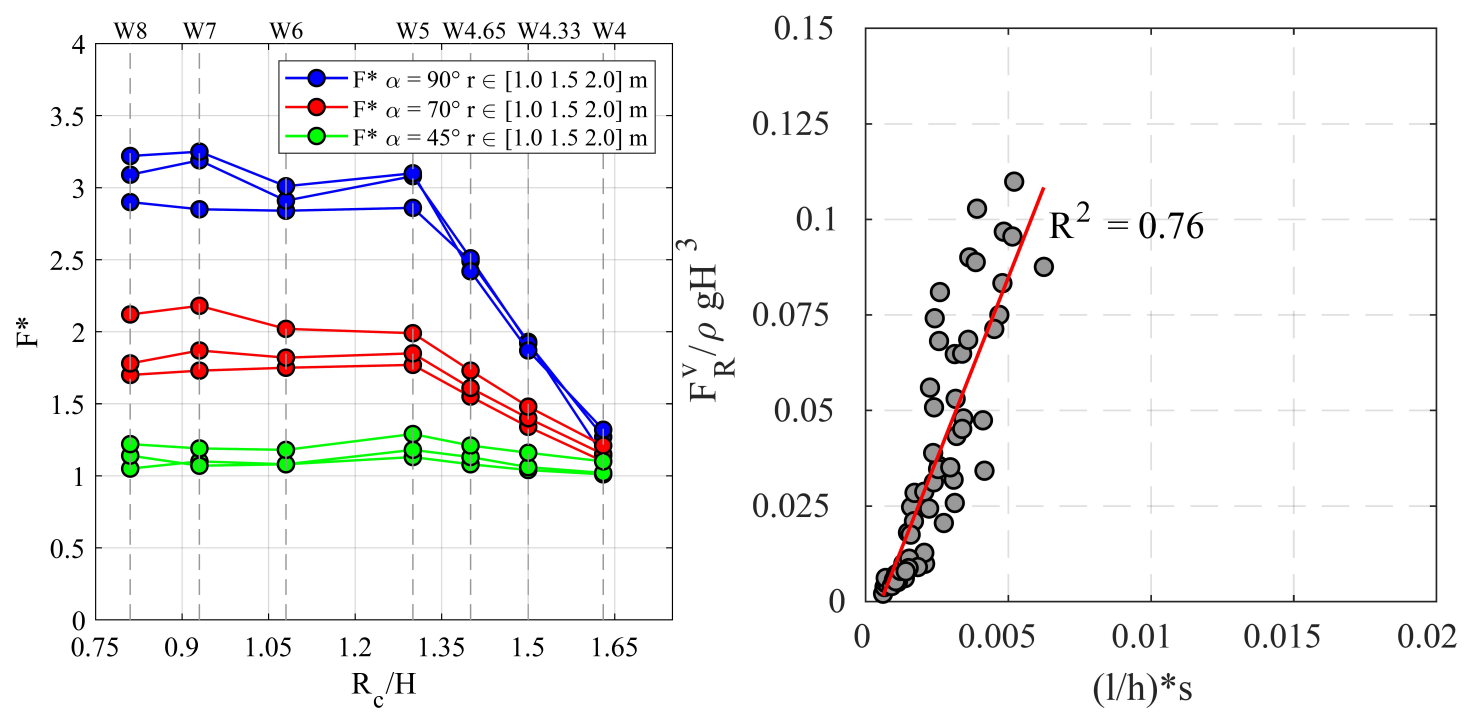

Figure 7. Left panel: Non-dimensional force as a function of the non-dimensional freeboard for the overall geometrical configurations. The blue group refers to the opening angle $\alpha=90^{\circ}$ and to the three radius of 1.0

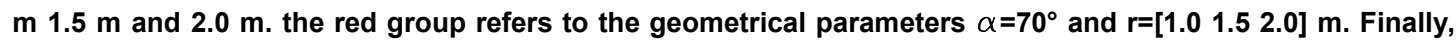
the green group refers to the opening angle $\alpha=45^{\circ}$ and to the radius equal to $1.0 \mathrm{~m}, 1.5 \mathrm{~m}$ and $2.0 \mathrm{~m}$. Right panel: non-dimensional vertical force component as a function of the non-dimensional parameter $(\mathrm{l} / \mathrm{h})^{*} \mathrm{~s}$, where $\mathrm{I}, \mathrm{h}$ and $\mathrm{s}$ represent the overhang, the water depth and the wave steepness in deep-water conditions.

A sensitivity analysis has been performed, varying the geometrical parameters a and $r$ (opening angle and radius). As a conclusion, a strong dependence of the force increase on the opening angle variations has been found, as shown in Figure 7 (left panel). Moreover, a relation between the vertical force component and the overall hydraulic and geometrical parameter is shown in Figure 7 (right panel). Further analysis are required to a complete comprehension of the physical process to provide some guidances for the design solutions. 


\section{REFERENCES}

Anand, K., V. Sundar, and S. Sannasiraj, Dynamic pressures on curved front seawall models under random waves, Journal of Hydrodynamics, Ser. B, $22,538\{544,2010\}$.

Berberovic, E., van Hinsberg, N.P., Jakirlic, S., Roisman, I.V., Tropea, C., 2009. Drop impact onto a liquid layer of finite thickness: dynamics of the cavity evolution. Phys. Rev. 79 (3), 036306.

Castellino, M., P. Sammarco, A. Romano, L. Martinelli, P. Ruol, L. Franco, and P. De Girolamo, Large impulsive forces on recurved parapets under non-breaking waves. A numerical study, Coastal Engineering, 136, 1-15, 2018.

Cuomo, G., W. Allsop, T. Bruce, and J. Pearson, Breaking wave loads at vertical seawalls and breakwaters, Coastal Engineering, 57, 424-439, 2010a.

Cuomo, G., W. Allsop, and S. Takahashi, Scaling wave impact pressures on vertical walls, Coastal Engineering, 57, 604-609, 2010b.

Cuomo, G., R. Piscopia, and W. Allsop, Evaluation of wave impact loads on caisson breakwaters based on joint probability of impact maxima and rise times, Coastal Engineering, 58, 9-27, 2011.

De Gerloni, M., L. Franco, A. Noli, and U. Rossi, Industrial port of Porto Torres: model test on the new west caisson breakwater (in Italian), in II AIOM Congress, Napoli, Italy, 1989.

De Girolamo, P., A. Noli, and D. Spina, Field measurements of loads acting on smooth and perforated vertical walls, in Advances in Coastal Structures and Breakwaters: Proceedings of the International Conference Organized by the Institution of Civil Engineers and Held in London on 27-29 April 1995, vol. 7, p. 64, Thomas Telford, 1996.

Di Risio, M., G. Beltrami, and P. De Girolamo, Laboratory investigation on wave overtopping of composite breakwaters: The port of Civitavecchia case, International Conference on Coastal Engineering, pp. 4616-4627, 2007.

Di Risio, M., G.-M. Beltrami, P. De Girolamo, A. Noli, and G. Ievolella, Investigation on overtopping and reflection performance of perforated caisson breakwaters: The Ponza Harbour case, in Coastal Structures 2007: (In 2 Volumes), pp. 1562-1573, World Scientific, 2009.

Elsafti, H., and H. Oumeraci, Analysis and classification of stepwise failure of monolithic breakwaters, Coastal Engineering, 121, 221-239, 2017.

Franco, L., M. De Gerloni, and J. Van der Meer, Wave overtopping on vertical and composite breakwaters, in Coastal Engineering 1994, pp. 1030-1045, 1995.

Franco, L., F. Arena, O. Mazzola, and L. Petrosemolo, The new deepwater Marina di Cicerone at Formia (i), in ICE Conference Coasts, Marine Structures and Breakwaters 2013, Thomas Telford, 2013.

Goda, Y., Random seas and design of maritime structures, World scientific, 2010.

Higuera, P., Lara, J.L., Losada, I.J., 2013a. Realistic wave generation and active wave absorption for Navier-Stokes models: application to openfoam ${ }^{\circledR}$. Coast. Eng. 71, 102-118.

Higuera, P., Lara, J.L., Losada, I.J., 2013b. Simulating coastal engineering processes with Openfoam ${ }^{\circledR}$ Coast. Eng. 71, 119-134.

Higuera, P., Lara, J.L., Losada, I.J., 2014a. Three-dimensional interaction of waves and porous coastal structures using openfoam ${ }^{\circledR}$. part i: formulation and validation. Coast. Eng. 83, 243-258.

Higuera, P., Lara, J.L., Losada, I.J., 2014b. Three-dimensional interaction of waves and porous coastal structures using openfoam ${ }^{\circledR}$. part ii: Application. Coast. Eng. 83, 259-270.

Kortenhaus, A., R. Haupt, and H. Oumeraci, Design aspects of vertical walls with steep foreland slopes, in Breakwaters, Coastal Structures and Coastlines: Proceedings of the International Conference Organized by the Institution of Civil Engineers and Held in London, UK on 26-28 September 2001, p. 221, Thomas Telford, 2002.

Kortenhaus, A., J. Pearson, T. Bruce, N. Allsop, and J. Van der Meer, Influence of parapets and recurves on wave overtopping and wave loading of complex vertical walls, in Coastal Structures 2003 , pp. 369-381, 2004.

Kortenhaus, A., et al., Wave overtopping and wave-induced loads on coastal sea walls, in Coastal Structures and Solutions to Coastal Disasters Joint Conference 2015, American Society of Civil Engineers (ASCE), 2015.

Lara, J. L., Losada, I. J., Guanche, R., 2008. Wave interaction with low-mound breakwaters using a rans model. Ocean Engineering 35 (13), 1388-1400. 
Lara, J. L., Ruju, A., Losada, I. J., 2011. Reynolds averaged Navier-Stokes modelling of long waves induced by a transient wave group on a beach. Proceedings of the Royal Society of London A: Mathematical, Physical and Engineering Sciences.

Martinelli L., Ruol P., Volpato M., Favaretto C., Castellino M., De Girolamo P., Franco L., Romano A., and Sammarco P., 2018. Experimental investigation on non-breaking wave forces and overtopping at the recurved parapets of vertical breakwaters. Coastal Engineering, 141:52-67.

Takahashi, S., Design of vertical breakwaters. Breakwater design, in International Conference On Coastal Engineering, Orlando, Short Course, 1996.

Van Doorslaer, K., A. Romano, J. De Rouck, and A. Kortenhaus, Impacts on a storm wall caused by non-breaking waves overtopping a smooth dike slope, Coastal Engineering, 120, 93-111, 2017. 